\title{
Potential Renoprotective Effects of Silymarin Against Nephrotoxic Drugs: A Review of Literature
}

\author{
Foroud Shahbazi ${ }^{1}$, Simin Dashti-Khavidaki ${ }^{2,3}$, Hossein Khalili ${ }^{2}$, Mahboob Lessan-Pezeshki ${ }^{4}$ \\ ${ }^{1}$ Resident of Clinical Pharmacy, School of Pharmacy, Tehran University of Medical Sciences, Tehran, Iran. \\ ${ }^{2}$ Associate Professor of Clinical Pharmacy, School of Pharmacy, Tehran University of Medical Sciences, Tehran, Iran. \\ ${ }^{3}$ Nephrology Research Center, Tehran University of Medical Sciences, Tehran, Iran. \\ ${ }^{4}$ Professor of Nephrology, Nephrology Research Center, Tehran University of Medical Sciences, Tehran, Iran.
}

Received, December 15, 2011; Accepted, January 16, 2012; Published, January 16, 2012.

\begin{abstract}
Drug-induced nephrotoxicity (DIN) accounts for up to sixty percent of hospital acquired acute kidney injury. Several efforts have been made to reduce drug-induced renal damage; however, DIN remains a matter of concern, with substantial impact on patients and the health system. Silymarin is a drug that has been used for many years in alternate and modern medicine for treating hepatic diseases. Its antioxidant, antiinflammatory and anti-apoptotic effects make it an interesting herbal medicine, and these properties have implicated this compound as a potential renoprotective agent. Based on the findings from animal studies, this review concluded that silymarin might exert significant protective or ameliorative effects against drug-induced kidney disease, especially against cisplatin-induced renal damage. Whether the protective administration of silymarin could be an effective clinical pharmacological strategy to prevent DIN is a question that remains to be answered in clinical trials.
\end{abstract}

This article is open to POST-PUBLICATION REVIEW. Registered readers (see "For Readers") may comment by clicking on ABSTRACT on the issue's contents page.

\section{INTRODUCTION}

Drug-induced nephrotoxicity (DIN) is a major cause of acute kidney injury (AKI). DIN has been implicated in up to $20 \%$ of hospital admissions due to AKI and in $8-60 \%$ of in-hospital AKI. Druginduced kidney disease is recognized as a main cause of mortality and morbidity (1). Several common mechanisms have been proposed for DIN, including altered intra-glomerular hemodynamics, tubular cell toxicity, inflammation (i.e., glomerulonephritis, acute and chronic interstitial nephritis), crystal nephropathy, rhabdomyolysis and microangiopathy. In addition, patient-specific or drug-related factors may predispose certain patients to drug-induced kidney injury.

Patient-related risk factors include decreased effective intravascular volume, old age, concurrent use of several nephrotoxic agents, diabetes mellitus, heart failure and underlying renal dysfunction. In addition, several therapeutic agent groups, such as chemotherapeutic drugs, aminoglycosides, amphotericin B, radiocontrast agents, calcineurin inhibitors and non-steroidal anti-inflammatory drugs (NSAIDs) are also commonly recognized as nephrotoxic medications. Preventive strategies, such as hydration (especially in volume deficient patients), avoidance of concurrent use of nephrotoxic drugs, drug dose adjustment based on kidney function, use of alternative medication with no or less nephrotoxic potential and preventive administration of antioxidant drugs, have been proposed to minimize DIN; however, DIN still remains a significant cause of morbidity and mortality $(1,2)$.

Silybum marianum, also known as milk thistle, is a member of Asteraceae family and is well recognized as a hepatoprotective herbal medicine. Silymarin is a lipophilic extract of the milk thistle seeds. It is composed of three isomers of flavonolignans (silybin, silydianin, and silychristin), and two flavonoids (taxifolin and quercetin) $(3,4)$.

Corresponding Author: Simin Dashti-Khavidaki, Associate Professor of Clinical Pharmacy, School of Pharmacy, Tehran University of Medical Sciences; and Nephrology Research Center, Imam Khomeini Hospital Comlex, Tehran University of Medical Sciences, Tehran, Iran. E-mail: dashtis@sina.tums.ac.ir 
Silymarin is commonly prescribed in cases of cirrhosis, viral hepatitis and Amanita phaloides poisoning (4-6).

Two major mechanisms have been proposed to account for the hepatoprotective effects of silymarin. The first mechanism is due to its dosedependent antioxidant effect. This effect is mediated by scavenging of free radicals, decreasing formation of reactive oxygen species (ROS) and inhibition of fatty acid peroxidation. The second mechanism involves anti-inflammatory and antiapoptotic actions through interference with nuclear factor kappa-B (NF- $\mathrm{B}$ ), modulation of inducible nitric oxide and decreases in cyclooxygenase-2 expression. Silymarin also possesses antiviral and anti-fibrotic effects $(6,7)$.

As noted, silymarin has shown promising hepatoprotective effects, both experimentally and clinically. Antioxidant and anti-inflammatory properties of silymarin may also have protective role against photocarcinogens (7) and nephropathic processes (3). Silybin has been found to stimulate kidney cells in a similar manner to that seen in liver cells. Silybin and silychristin have been shown to increase proliferation rate, protein and DNA biosynthesis and lactate dehydrogenase (LDH) activity in kidney cells that have been damaged in vitro by paracetamol, cisplatin or vincristine. Administration of silybin prior to or following the chemical-induced injury has prevented or reduced nephrotoxic effects (8).

Silymarin therefore appears to have the potential as a renoprotective agent against nephrotoxic medications due to its antioxidant, antiinflammatory and anti-apoptotic actions. The protective effects of silymarin on drug-induced nephrotoxicity have been investigated to date primarily in animals, with renoprotection against cisplatin being most frequently reported. This manuscript reviews the available articles that have examined the nephroprotective effects of silymarin against a number of nephrotoxic drugs.

\section{METHODS}

The present review evaluated and critiqued all of the available in vitro and in vivo studies that examined the use of silymarin as a renoprotective agent. Materials for this review were obtained by searching Medline, PubMed, Scopus, Cochrane central register of controlled trials, and Cochrane database of systematic reviews. Key words used as search terms included "silymarin", "milk thistle", "Silybum marianum", "silybin", "silibinin", "nephrotoxicity", "acute kidney injury", "nephropathy" , "renoprotective", and "nephroprotective". This search was performed without time limitation.

\section{Silymarin and Cisplatin-Induced Nephrotoxicity}

Cisplatin is a potent chemotherapeutic agent that has been widely used to treat many solid tumours such as head, neck, lungs, testis, ovary and breast cancers. Nephrotoxicity is a major and doselimiting side effect of cisplatin, with an incidence reported as 6-13\% (1). Renal side effects of cisplatin include AKI, Fanconi-like syndrome, distal renal tubular acidosis, hypomagnesemia, hypocalcemia, renal salt wasting, renal concentrating defect, hyperuricemia, transient proteinuria, erythropoietin deficiency, thrombotic microangiopathy and chronic renal failure (9). Cisplatin-induced nephrotoxicity is mainly mediated through drug transport into renal epithelial cells, which subsequently causes injury to nuclear and mitochondrial DNA, activation of cell apoptosis and necrosis, and stimulation of inflammatory responses (9-11). Cisplatin induced production of ROS has also been implicated in its nephrotoxicity (12). The major inflammatory factor involved in cisplatin-induced nephrotoxicity is TNF- $\alpha(2,12)$. The production of TNF- $\alpha$ is highly dependent on ROS and NF- $\kappa B$ activation (13).

Based on our literature review, the first research on renoprotective effects of silymarin against cisplatin- induced renal damage was carried out by Gaedeke et al in 1996. They induced cisplatin nephrotoxicity in female Wistar rats by single intravenous (IV) injection of $5 \mathrm{mg} / \mathrm{kg}$ cisplatin in two groups of rats. One group received $200 \mathrm{mg} / \mathrm{kg}$ of IV silybin one hour before cisplatin injection. Normal saline and silybin control groups were also incorporated into the study. Rats were killed five days after drug injections. Cisplatin caused a decrease in creatinine clearance and an increase in proteinuria, urinary activity of the proximal tubular enzymes (alanine aminopeptidase and $\mathrm{N}$-acetyl- $\beta$ D-glucosaminidase) and fractional excretion of magnesium. Pre-treatment of rats with silybin completely prevented the decline in creatinine clearance and proteinuria and partially ameliorated 
proximal tubular impairment such as enzymuria and magnesuria. Silybin also diminished morphological changes in the S3-segment of the proximal tubules and protected the kidney from tubular necrosis.

Since other research had shown that vitamin E, an antioxidant vitamin, could not prevent cisplatininduced tubular toxicity, the authors concluded that antioxidant property of silybin is not the major mechanism behind renoprotective action of this flavonoid against cisplatin-induced nephrotoxicity. They proposed that the toxicity of cisplatin to tubules may be due to depression of DNA, RNA, and protein synthesis by this drug. They postulated that silybin might ameliorate this toxicity by upregulation of DNA-dependent RNA polymerase I, thereby increasing the numbers of ribosomes, and as a result, counteracting the decrease in macromolecule synthesis in the kidney (14).

These same investigators, in a subsequent study, showed that nephroprotective effect of silybin does not compromise anti-tumour activity of cisplatin (15). Silybin also showed a dosedependent improvement in cisplatin cell toxicity indices such as cisplatin-induced inhibition of cell growth, LDH activity, and protein biosynthesis in Vero kidney cells of the African green monkey (8). An in vitro study by Sonnenbichler et al in 1999 showed that silybin and silychristin administered to Vero kidney cells had significant stimulatory effects on cell proliferation rate, DNA and protein biosynthesis and the activity of $\mathrm{LDH}$, used as a cellular metabolic marker. When this cell line was damaged by various toxins, silybin again showed protective effects. In this research, the concentration dependence of cisplatin toxicity was determined to reach suitable inhibition of cell activities. Compared to silybin administration after cisplatin, silybin injection into the cell culture before cisplatin administration showed more cell protective effects (8).

An animal study by Karimi et al (2005), using six groups of male Wistar rats, evaluated renoprotective effects of milk thistle and its methanolic extract against cisplatin-induced renal toxicity. Nephrotoxicity was induced by single intraperitoneal (IP) administration of $3 \mathrm{mg} / \mathrm{kg}$ of cisplatin. Group one just received cisplatin. Group two and three received $0.6 \mathrm{~g} / \mathrm{kg}$ of methanolic extract of milk thistle or $50 \mathrm{mg} / \mathrm{kg}$ of milk thistle 2 hours before cisplatin administration, respectively. Groups 4 and 5 received the same doses of extract or milk thistle 2 hours after cisplatin injection, respectively. Group 6 just received vehicles as control. Rats were killed five days after cisplatin administration. Blood urea nitrogen (BUN) and serum creatinine ( $\mathrm{SCr}$ ) were assessed as markers of kidney function. Tubulo-interstitial areas were also evaluated histologically. Administration of milk thistle or its extract before cisplatin injection prevented both functional and tubular nephrotoxicity by cisplatin. Administration of milk thistle or its extract after cisplatin significantly prevented $\mathrm{SCr}$ or BUN increments, but resulted in mild to moderate cell injury, based on histological findings. The authors concluded that the renal toxicity of cisplatin occurs by a rapid process that may not be completely prevented by delayed administration of silymarin (16).

In a similar manner, Abdelmeguid et al evaluated the protective effects of silymarin on cisplatin-induced nephrotoxicity. Their five groups of male Sprague Dawley rats included control, vehicle-administered, cisplatin-administered, silymarin (administered 2 hours after cisplatin was injected), and silymarin (administered 2 hours before cisplatin was injected) treatments. Silymarin and cisplatin were dosed at $50 \mathrm{mg} / \mathrm{kg}$ and $5 \mathrm{mg} / \mathrm{kg}$ respectively. Body weight gain, kidney wet weight, behavioural changes and histopathological studies were measured to evaluate cisplatin-induced nephrotoxicity. Reduced food intake and body weight, increased kidney wet weight (manifested as elevated kidney to body weight ratio), atrophied glomerular basement membranes and tubular cell vacuolization indicated significant renal toxicity in the cisplatin group. Silymarin treated groups (either $2 \mathrm{~h}$ before or $2 \mathrm{~h}$ after cisplatin) had markedly lowered kidney wet weights. Histological findings showed that pretreatment with silymarin may block cisplatin-induced nephrotoxicity. In the group that received silymarin $2 \mathrm{~h}$ after cisplatin administration, only mild to moderate renal injury was noted (17).

As stated before, the flavonoid quercetin is one of the compositions of milk thistle. Behling et al in 2006 reported protective effect of quercetin when administered before cisplatin injection in male Wistar rats. Quercetin attenuated cisplatin-induced nephrotoxicity, including increased lipid peroxidation, plasma creatinine level and urine volume, and decreased urine osmolality. Quercetin also somewhat reduced cisplatin-induced structural alterations in the renal cortex and outer medulla, as 
well as histological features of cisplatin-induced chronic nephropathy, such as interstitial fibrosis, and tubular atrophy or dilatation. Antioxidant properties of quercetin were proposed to underlie the mechanism of these renoprotective effects (18).

In a recent study by Sanchez-Gonzalez, quercetin renoprotective effects were assessed in male Fischer rats that were inoculated by breast adenocarcinoma cells (13762 Mat B-III).These rats were pretreated with daily IP administration of quercetin $(50 \mathrm{mg} / \mathrm{kg})$ for four days, and then a single IP dose of $4 \mathrm{mg} / \mathrm{kg}$ of cisplatin was administered. Kidneys and tumours were assessed two to six days later. Renal function and structure were assessed using renal blood flow, glomerular filtration rate, tubular necrosis/apoptosis, lipid peroxidation, antioxidant capacity and inflammatory status. A renoprotective effect of quercetin against cisplatin occurred without reducing the anti-tumour activity of this drug (19). A lack of negative interference of silymarin with anti-tumour effects of drugs has been reported by other researchers as well (20). In fact, silymarin and its main flavonolignan, silybin, have shown both in vivo and in vitro anticancer effects against skin, breast, lungs, colon, bladder, prostate and kidney carcinomas (21).

Ninsontia et al showed a protective effect of silymarin against cisplatin-induced cell apoptosis, necrosis and death in a renal proximal tubular HK-2 cell-line. In this study, cellular apoptosis and necrosis were evaluated using Hoechst 33342 and propidium iodide and cell vitality was assessed by 3-(4,5-dimethyl-2-yl)-2,5-diphenyltetrazolium bromide. Cisplatin induced both apoptosis and necrosis in HK-2 cells and decreased cell viability by about $40 \%$ and $60 \%$, at the doses of 25 and 100 micromolar $(\mu \mathrm{M})$, respectively. Silymarin administration at doses of $25-200 \mu \mathrm{M}$ to these cell lines before cisplatin injection significantly protected these cells against cisplatin-induced cell death in a dose-dependent manner. Cisplatininduced HK-2 cytotoxicity was apparently due to apoptotic and necrotic cell death. This study also showed that silymarin at increased concentrations of 100-200 $\mu \mathrm{M}$ exerted anti-cancer activity against lung cancer H460 and melanoma G361cell lines through increased apoptosis and it also potentiated cisplatin-induced damage in melanoma cells (22).
These studies all indicate that silymarin reduces the nephrotoxic effects of cisplatin without decreasing its anti-tumour activity. The renoprotective effects of silymarin were more apparent when it was administered before cisplatin. Based on these studies, it would seem to be the time to start randomized human clinical trials for assessing the clinical renoprotective impact of this herbal medicine against the valuable chemotherapeutic agent cisplatin.

\section{Silymarin and Doxorubicin - Induced Nephrotoxicity}

Doxorubicin, an anthracycline, is widely used to manage several malignancies, mainly Hodgkin lymphoma and breast cancer. Although cardiac toxicity is the main dose-limiting adverse effect of doxorubicin prescription, nephrotoxicity should not be neglected. Research by El-Shitany showed that nephrotoxicity was induced by a single IP injection of $10 \mathrm{mg} / \mathrm{kg}$ of doxorubicin to male Albino rats. Doxorubicin caused significant increases in plasma creatine phosphokinase (CPK), LDH, creatinine, and urea concentrations. Reduced glutathione (GSH) levels were decreased significantly as well in the kidney. Microscopic examination of the kidneys one month after doxorubicin administration showed tubular congestion, tubular cast, interstitial hemorrhage, vascular tubular degeneration, glomerular congestion with wide Bowman's space, and proximal tubular degeneration. A group of rats pretreated with $50 \mathrm{mg} / \mathrm{kg}$ of silymarin one week before doxorubicin injection and daily thereafter for one month showed a marked reduction in plasma CPK and $\mathrm{LDH}$, by $82 \%$ and $43 \%$, respectively, compared to the doxorubicin-treated group. Silymarin also caused a decrease in plasma creatinine and urea levels and an increase in kidney GSH concentration to near their control values. Microscopic examination of the kidneys of the silymarin pretreated group revealed only mild renal tissue swelling. Doxorubicin-induced cardiotoxicity and nephrotoxicity were proposed to be the result of formation of an iron-doxorubicin complex that generates free radicals and ROS and causes oxidative damage to the cellular components and lipid membranes. Silymarin may counteract this damage through its antioxidant and ROS scavenging properties (23). 


\section{Silymarin and Vincristine-Induced Nephrotoxicity}

Vincristine, a cytotoxic alkaloid, has been used as a therapy for various types of malignancies. Administration of silybin before or after vincristine injection to Vero kidney cells of African green monkey ameliorated vincristine-induced reduction in cell growth and LDH activity. These nephroprotective effects were more pronounced when silybin was administered before vincristine injection in this cell line culture (8).

\section{Silymarin and Aminoglycoside - Induced Nephrotoxicity}

Aminoglycosides are generally known as most potent nephrotoxic drugs. Aminoglycoside uptake occurs via internalization through megalin transporters. After internalization, aminoglycosides initiate a cascade of reactions that finally result in cell death. To date, increases in intracellular sodium concentration, reactive oxygen species and proinflammatory cytokines and in apoptosis, decreases in glucose, and depletion of adenosine triphosphate (ATP) storage have been proposed as being responsible for aminoglycoside-induced tubular, glomerular and vascular damage. In the renal tubules, aminoglycosides may interfere with mitochondrial function and compromise ATP production. Induction of apoptosis and ultimately necrosis of tubular epithelial cells have been implicated in tubular toxicity.

In the glomerulus, aminoglycosides may decrease glomerular filtration rate through mesangial contraction, stimulation of mesangial proliferation and neutralization of negative charges of the glomerular filtration barrier. An increase in vasoconstrictor mediators, including increases in angiotensin-II, endothelin-I, thromboxane A2 and ROS, and decreases in vasodilator prostaglandins, have been proposed to explain aminoglycosideinduced vascular dysfunction. The net effects of aminoglycosides on kidney are therefore apparently mediated by vasoconstrictors, ROS, inflammatory cytokines and apoptosis. Aminoglycoside-induced nephrotoxicity may be non-oliguric or polyuric and its clinical presentations include increased serum creatinine and urea concentrations, proteinuria, enzymuria, glycosuria, hypomagnesemia and hypocalcemia (24).
Varzi and colleagues evaluated silymarin effects on gentamicin-induced nephrotoxicity in a study of five groups of dogs. Group 1 was injected saline as control group. Groups 2 to 5 received intramuscular injection of $20 \mathrm{mg} / \mathrm{kg}$ of gentamicin sulfate once daily for 9 days. Group 3 was administered vitamin E orally at dosage of 25 $\mathrm{mg} / \mathrm{kg}$ once daily for 9 days. Group 4 received silymarin $20 \mathrm{mg} / \mathrm{kg}$ daily for 9 days. Group 5 was administered both vitamin $\mathrm{E}$ and silymarin at the same doses as groups 3 and 4 for 9 days. Rises in serum creatinine and urea levels and decreases in glomerular filtration rate were considered as markers of deteriorating renal function. Total serum antioxidant activity was also assessed as a marker of antioxidant defense capacity. The dogs that received silymarin concomitant with gentamicin had lower rises in serum creatinine and urea concentrations and higher glomerular filtration rates compared to the group that was administered gentamicin alone. Serum levels of malondialdehyde (MDA), a marker of lipid peroxidation, were also significantly lower and total serum antioxidant activity was higher in silymarin treated dogs. Interestingly, in this study, silymarin showed greater nephroprotective and antioxidant effects than did vitamin E (25).

\section{Silymarin and Cyclosporine - Induced Nephrotoxicity}

Cyclosporine, a calcineurin inhibitor, is the cornerstone of immunosuppressive therapy in many solid organ/bone marrow transplantation centers. Cyclosporine can induce both reversible and irreversible damage to all kidney compartments including glomeruli, arterioles, and the tubulointerstitium. Cyclosporine-induced renal dysfunction manifests as asymptomatic increases in serum creatinine concentration, acute renal failure, delayed recovery of renal graft function and hemolytic-uremic syndrome. Increase in angiotensin and endothelin concentrations, imbalance between vasodilatory/vasoconstrictory prostaglandins, and oxidative stress are thought to be responsible for cyclosporine-induced nephrotoxicity. Antioxidants were proposed as possible protective agents against cyclosporineinduced nephrotoxicity but human studies are still needed (26). 
Silybin appears to have the potential to inhibit lipid peroxidation and to promote free radical scavenging. Since some researchers attributed cyclosporine-induced nephrotoxicity to lipid peroxidation and effects on cytochrome P-450, Zima et al hypothesized a possible role for silybin in preventing cyclosporine-induced nephrotoxicity. They induced cyclosporine nephrotoxicity by IP administration of $30 \mathrm{mg} / \mathrm{kg}$ of this drug in rats. One group of rats received $5 \mathrm{mg} / \mathrm{kg}$ of silybin 30 minutes before cyclosporine injection. Although silybin administration reduced the rise in plasma and kidney MDA concentrations compared to cyclosporine alone group, it did not prevent glomerular filtration rate reduction due to cyclosporine (27).

Satyanarayana and colleagues examined the possible protective role of quercetin, one of the bioflavonoid components of silymarin, on cyclosporine-induced nephrotoxicity. They produced a rat model of cyclosporine nephrotoxicity by injecting $20 \mathrm{mg} / \mathrm{kg}$ cyclosporine subcutaneously for 21 days. The quercetin treated groups received 0.5 or $2 \mathrm{mg} / \mathrm{kg}$ of quercetin one day before and then concurrently with cyclosporine daily for 21 days. Tissue lipid peroxidation was assessed by thiobarbituric acid reacting substances (TBARS). Plasma creatinine and urea concentrations and creatinine and urea clearances were assessed to evaluate kidney function. Cyclosporine injection resulted in a significant rise in plasma creatinine and urea levels and a decrease in creatinine and urea clearances in rats. Morphological studies showed severe interstitial fibrosis, arteriopathy, glomerular basement membrane thickening and tubular vacuolization in these animals. The quercetin group showed significant preservation of kidney function and structure, based on evaluation of these parameters. The antioxidant properties of quercetin were viewed as contribution to the underlying nephroprotective mechanism (28).

\section{Silymarin and Acetaminophen - Induced Nephrotoxicity}

Acetaminophen, an effective painkiller, may exert some renal side effects, especially chronic interstitial nephritis $(2,29)$. Vero kidney cells that were intoxicated with different concentrations of acetaminophen responded to the addition of silybin with a significant decrease in the inhibitory effects of acetaminophen on protein biosynthesis and proliferation rate. Better results were noted when higher concentrations of silybin $(40 \mu \mathrm{M}$ versus 20 $\mu \mathrm{M})$ were injected (8). Ramachandran et al evaluated milk thistle effects on nephrotoxicity induced by a single IP dose of $750 \mathrm{mg} / \mathrm{kg}$ acetaminophen in male Wistar albino rats. In this study, silymarin was used as a standard renoprotective agent. Oral silymarin administrations at a $50 \mathrm{mg} / \mathrm{kg}$ dosage significantly improved kidney function indices such as plasma urea, creatinine and uric acid concentrations. Markers of antioxidant activities such as of superoxide dismutase, catalase and glutathione peroxidase were mildly decreased and maintained near normal ranges in the animal group that received silymarin (30).

Studies that have evaluated the renoprotective effects of silymarin against drug-induced nephrotoxicity are summarized in table 1 .

\section{DISCUSSION}

About $60 \%$ of hospital-acquired acute kidney injury can be accounted for by drug-induced nephrotoxicity, which is a main cause of mortality and morbidity. Several options, such as dose adjustment based on renal function, hydration and avoidance of nephrotoxic agents, have been proposed to prevent or ameliorate drug-induced nephrotoxicity $(1,2)$. Nevertheless, DIN remains a major problem for health care professionals.

Silymarin is widely used as a hepatoprotective remedy. Antioxidant and anti-inflammatory actions; protein synthesis induction; inhibition of lipid peroxidation, leukotriene and prostaglandin synthesis; and neutrophil migration are among the pharmacologically described effects of silymarin bioflavonoids $(5,6,31)$. Silymarin may exert positive effects in the management of patients with renal insufficiency. Recently, Roozbeh et al reported that treatment of hemodialysis patients with silymarin, alone or in combination with vitamin E, significantly decreased plasma MDA concentration and increased red blood cell glutathione peroxidase and hemoglobin levels (32). Silymarin also reduced kidney damage and restored activities of superoxide dismutase, glutathione peroxidase and catalase enzymes in rats with alloxan-induced diabetes (33). In streptozotocininduced diabetes rats, milk thistle extract attenuated 
diabetic nephropathy, probably by increasing catalase and glutathione peroxidase activity and reducing lipid peroxidation in renal tissue (34).

Renoprotective effects of silymarin against some chemical nephrotoxins other than drugs have also been reported. An animal model of chloroform induced nephrotoxicity was designed in SpragueDawley male rats by administering $20 \%$ chloroform in olive oil at dose of $2 \mathrm{ml} / \mathrm{kg}$ every other day. When silymarin was intragastrically administered at a dose of $50 \mathrm{mg} / \mathrm{kg}, 24$ hours after IP administration for two weeks, a significantly restored renal function was observed, based on the urine and serum markers of kidney function (urea, creatinine, creatinine clearance, protein, albumin, urobilinogen, and nitrite). Silymarin treatment also restored losses in body weight and rises in kidney weight that had been induced by chloroform (35).

Female Swiss albino mice fed with silymarin and ferric nitrilotriacetate, a potent nephrotoxic agent and a renal carcinogen, showed lower rates of lipid peroxidation, kidney cell hyper proliferation, and expression of proinflammatory mediators compared with the group that received ferric nitrilotriacetate alone (36). Conversely, silymarin exacerbated renal impairment in an animal model of glycerol-induced acute kidney injury. In that study, silymarin administration resulted in persistence of oxidative stress and inflammatory processes, tubular necrosis and apoptosis in rats with glycerolinduced AKI (37).

Another renoprotective impact of silymarin includes preventive effects against ischemia/reperfusion (I/R) renal injury. Silymarin dose-dependently prevented $I / R$ induced renal morphology changes in Sprague-Dawley rats, including tubular dilatation and vacuolization, pelvic inflammation, interstitial inflammation, perirenal adipose infiltration and tubular and glomerular necrosis (38). Silymarin prevented I/R induced renal damage in Wistar rats based on other kidney markers such as serum creatinine, urea, and cystatin $\mathrm{C}$ concentrations, serum enzymatic activity of gluthathione peroxidase and serum and tissue MDA and NO levels (39).

Silymarin has also shown anticancer activities against renal cell carcinoma in some studies $(21,40,41)$. Possible mechanisms of silymarin anticancer effects include inhibition of cell proliferation, enhancement of apoptosis, decreases in angiogenesis, blockage of cell cycle regulators and increases in the expression of cell cycle inhibitors (21).

Silymarin is rapidly absorbed following oral administration and undergoes both phase I and especially phase II metabolism in the liver. Although silymarin reduces activities of some cytochrome P-450 isoenzymes, UDP-glucuronosyl transferase, and P-glycoprotein, no clinically significant drug interaction has yet been reported with usual dose of silymarin (42-44). Milk thistle extract has a good safety profile and most associated adverse events are mild in nature and include mild dyspepsia, allergic reactions, urticaria and nausea. Pruritus, headache, exanthema, malaise, asthenia and vertigo have been reported less frequently following silymarin administration (45, 46).

In conclusion, most of the studies of silymarin are suggestive of promising positive effects on drug-, chemical-, and to some extent, diseaseinduced nephropathy. Due to the high burden that DIN places with respect to patient morbidity, mortality, and health-related costs, silymarin may be recommended as a renoprotective agent to attenuate toxicity of some valuable drugs such as cisplatin and aminoglycosides that currently have a high likelihood of inducing nephrotoxicity.

\section{Limitations}

In this review, we have presented articles that evaluate protective effects of milk thistle bioflavonoids against drug-induced nephrotoxicity. All of the available articles are animal and in vitro cellular studies, which makes generalization to human subjects difficult.

\section{Future Perspectives}

Drug induced nephrotoxicity is a well-recognized cause of acute kidney injury; hence, its prevention is a matter of significant clinical relevance. Few medical options are available to prevent DIN. New animal data show the beneficial effects of silymarin on the prevention or reduction of nephrotoxicity induced by a number of important drugs such as cisplatin, doxorubicin, vincristine, acetaminophen and aminoglycosides. Major studies that focused on the use of silymarin as a nephroprotective agent have been reviewed in this article. Almost all of these studies showed that silymarin administration 
to animals reduced or prevented DIN. Randomized clinical trials should now be designed to assess the renoprotective effects of milk thistle against nephrotoxic drugs, by using more accurate and rapid markers of renal damage than serum urea and creatinine (e.g., cystatin $\mathrm{C}$, neutrophil gelatinaseassociated lipocalin, kidney injury molecule-1, and interleukin-18) and by evaluating the nephroprotective impact of silymarin at different sites of the nephron.

\section{ACKNOWLEDGEMENT}

There is no financial support for this study and the authors declare no conflict of interest.

\section{REFERENCES}

1. Dolin, TD. andHimmelfarb, J., Drug-induced kidney disease, in Dipiro JT(eds), Pharmacotherapy, a pathophysiologic approach, $7^{\text {th }}$ ed., Mc Graw Hill companies Inc,New York, pp795-810,2008.

2. Cynthia A. Naughton . Drug-Induced Nephrotoxicity. Am Fam Physician, 78:743750,2008 .

3. Vladimir Kren, Daniela Walterova. Silybin and silymarin- new effects and applications. Biomed Papers, 149(1):29-41, 2005.

4. Ludovico Abenavoli, Raffaele Capasso, Natasa Milic, Francesco Capasso. Milk thistle in liver disease: past, present, future. Phytother Res, 24(10): 1423-1432, 2010.

5. Carmela Loguerico, DavideFesti. Silybin and the liver: from basic research to clinical practice. World J Gastroenterol, 17(18): 2288-2301,2011.

6. Reinhard Saller, Remy Meier, Reto Brignoli. The use of silymarin in the treatment of liver diseases. Drugs. 61(14): 2035-2063,2001.

7. Mudit Vaid, Santosh K. Katiyar. Molecular mechanisms of inhibition of photocarcinogenesis by silymarin, a phytochemical from milk thistle (Silybum marianum L. Gaertn)(Review). Int Journal Oncol, 36(5): 1053-1060,2010.

8. Johann Sonnenbichler, Fortunato Scalera, Isolde Sonnenbichler, Roland Weyhenmeyer. Stimulating effects of silibinin and silicristin from themilk thistle Silybum marianum on kidney cells. J Pharm Exp Ther, 290: 1375-1383,1999.

9. Ronald P Miller, Raghu K Tadagavadi, Ganesan Ramesh, William Brain Reeves. Mechanisms of cisplatin nephrotoxicity. Toxins,2: 2490-2518,2010.

10. N Pabla N, Z Dong. Cisplatin nephrotoxicity: mechanisms and renoprotective strategies. Kidney Int, 73(9):994-1007,2008.
11. Fumie Shiraishi, Lisa M. Curtis, Leigh Truong, Kenneth Poss, Gary A. Visner, Kirsten Madasen, Harry S. Nick, Anupam Agarwal. Heme oxygenase1 gene ablation or expression modulates cisplatininduced renal tubuar apoptosis. Am J Physiol Renal Physiol, 278: F726-F736,2000.

12. Christopher A. Dasis, Harry S. Nick, Anupam Agarwal. Manganese superoxide dismutase attenuates cisplatin-induced renal injury: importance of superoxide. J Am Soc Nephrol, 12: 26832690,2001 .

13. Ganesan Ramesh, William Brain Reeves. P38 MAP kinase inhibition ameliorates cisplatin nephrotoxicity in mice. Am J Physiol Renal Physiol, 289: F166-F174,2005.

14. J Gaedeke, LM Fels, C Bokemeyer, U Mengs, H Stolte, $\mathrm{H}$ Lentzen. Cisplatin nephrotoxicity and protection by silibinin. Nephrol Dial Transplant, 11:55-62,1996.

15. C Bokemeyer, L.M Fels, T Dunn, W Voigt, J Gaedeke, H-J Schmoll, H Stolte, H Lentzen. Silibinin protects against cisplatin-induced nephrotoxicity without compromising cisplatin or ifosphamide anti-tumor activity. Br J Cancer, 74: 2036-2041,1996.

16. Gholamreza Karimi, Mohammad Ramezani, Zahra Tahoonian. Cisplatin nephrotoxicity and protection by milk thistle extract in rats. Evid Based Complement Alternat Med, 2:383-386,2005.

17. Nabia E. Abdelmeguid, Hania N. Chmaisse, Noura S. Abou Zeinab. Protective effect of silymarin on cisplatin-induced nephrotoxicity in rats. Pakistan Journal of Nutrition, 9(7):624-636,2010.

18. Estela B. Behling, Milena C. Sendao, Heloisa D.C. Francescato, Lusania M.G. Antunes, Roberto S. Costa, Maria de Lourdes P. Bianchi. Comparative study of multiple dosage of quercetin against cisplatin-induced nephrotoxicity in rat kidney. Pharmacol Rep, 58:526-532,2006.

19. Penelope D. Sanchez-Gonzalez, Francisco J. LopezHernandez, Fernando Perez-Barricanal, Ana I. Morales, Jose M. Lopez-Novoa. Quercetin reduces cisplatin nephrotoxicity in rats without compromising its anti-tumor activity. Nephrol Dial Transplant, 26(11):3484-3495,2011.

20. Valentina Colombo, Monica Lupi, Francesca Falcetta, Daniele Forestieri, Maurizio D'Incalci, Paolo Ubezio. Chemotherapeutic activity of silymarin combined with doxorubicin or paclitaxel in sensitive and multidrug-resstant colon cancer cells. Cancer Chemother Pharmacol, 67:369-379, 2011.

21. Catherine Wing Ying Cheung, Norma Gibbons, David Wayne Johnson, David Lawrence Nicol. Silibinin-A promising new treatment for cancer. 
Anticancer Agents Med Chem, 10(3): 186-195, 2010.

22. Chuanpit Ninsontia, Kanittha Pongjit, Chatchai Chaotham, Pithi Chanvorachote. Silymarin selectively protects human renal cells from cisplatininduced cell death. Pharm Biol, 49(10):1082-1090, 2011.

23. Nagla A. El-Shitany, Sahar El-Haggar, Karema ElDesoky. silymarin prevents adriamycin-induced cardiotoxicity and nephrotoxicity in rats. Food Chem Toicol, 46:2422-2428, 2008.

24. Jose M. Lopez-Novoa, Yaremi Quiros, Laura Vicente, Ana I. Morales, Francisco J. LopezHernandez. New insight into the mechanism of aminoglycoside nephrotoxicity: an integrative point of view. Kidney Int, 79: 33-45, 2011.

25. H.N. Varzi, S Esmailzadeh, H Morovvati, R Avizeh, A Shahriari, M.E. Givi. Effect of silymarin and vitamin $\mathrm{E}$ on gentamicin-induced nephrotoxicity. J Vet Pharmacol Therap, 30:477-481, 2007.

26. Maarten Naesens, Dirk R.S. Kuypers, Minnie Sarwal. Calcineurin inhibitor nephrotoxicity. Clin J Am Soc Nephrol, 4:481-508,2009.

27. Tom AS Zima, Ludmila Kamenikova, Marta Janebova, Evzen Buchar, Jirina Crkovska, Vladimir Tesar. The effect of silibinin on experimental cyclosporine nephrotoxicity. Ren Fail, 20(3): 471479,1998.

28. P.S.V. Satayanarayana, D. Singh, K. Chopra. Quercetin, a bioflavonoid, protects against oxidative stress-related renal dysfunction by cyclosporine in rats. Methods Find Exp Clin Pharmacol,4:175$181,2001$.

29. WWW.Uptodate.com, 19.3.

30. Vinayagam Ramachandran, Ramalingam Sarvanan, Boobalam Raja. Attenuation of oxidative stress by syringic acid on acetaminophen-induced nephrotoxic rats. Comp Clin Path, DOI 10.1007/s00580-0111327-z,2010.

31. Nitin Dixit, Sanjula Baboota, Kanchan Kohli, S. Ahmad, Javed Ali. Silymarin: A review of pharmacological aspects and bioavailability enhancement approaches. Indian J Pharmacol,39: 172-179,2007.

32. Jamshid Roozbeh, Bahram Shahriyari, Masoumeh Akmali, Ghazal Vessal, Maryam Pakfetrat, Ghanbar Ali Raees Jalali, Raha Afshariani, Mahshid Hasheminasab, Nasrollah Ghahramani. Comparative effects of silymarin and vitamin E supplementation on oxidative stress markers, and hemoglobin levels among patients on hemodialysis. Ren Fai,33(2): 118-123,2011.

33. C. Soto, J. Perez, V. Garcia, E. Uria, M. Vadillo, L. Raya. Effects of silymarin on kidneys of rats suffering from alloxan-induced diabetes mellitus. Phytomedicine, 17: 1090-1094,2010.
34. Ghazal Vessal, Masoumeh Akmali, Parisa Najafi, Mahmood Reza Moein, Mohmmad Mahdi Sagheb. Silymarin and milk thistle may prevent the progression of dibatic nephropathy in streptozotocin-induced diabetic rats. Ren Fail,32:733-739,2010.

35. Muhammad Rashid Khan, Fatima Siddique. Antioxidant effectsof Citharexylum spinosum in CCl4 induced nephrotoxicity in rat. Exp Toxicol Pathol, DOI:10.1016/j.etp.2010.09.009,2010.

36. Gurpeet Kaur, Mohammad Athar, M. Sarwar Alam. Dietary supplementation of silymarin protects against chemically induced nephrotoxicity, inflammation and renal tumor promotion response. Invest New Drugs, 28:703-713, 2010.

37. Eduardo Homsi, Silvano Machado de Brito, Patricia Janino. Silymarin exacerbates p53-mediated tubular apoptosis in glycerol-induced acute kidney injury. Ren Fail, 32:623-632, 2010.

38. Hakan Senturk, Sahin Kabay, Gokhan Bayramoglu, Hilmi Ozden, Faik Yaylak, Mehmet Yucel, esra Gurlek Olgun, Ali Kutlu. Silymarin attenuates the renal ischemia/reperfusion injury-related morphological changes in the rat kidney. World $\mathrm{j}$ Urol, 26: 401-407, 2008.

39. Faruk Turgut, Omer Bayrak, Farhat Catal, Reyhan Bayrak, Ali Fuat Atmaca, Akif Koc, Ali Akbas, Ali Akcay, Dogan Unal. Antioxidant and protective effects of silymarin on ischemia and reperfusion injury in the kidney tissues of rats. Int Urol Nephrol, 40:453-460, 2008.

40. Horng-Rong Chang, Pei-Ni Chen, Shun-Fa Yang, Ying-Sui Sun, Sheng-Wen Wu, Tung-Wei Hung, Jong-Da Lian, Shu-Chen Chu, Yih-Shou Hsieh. Silibinin inhibits the invasion and migration of renal carcinoma 786-O cells in vitro, inhibits the growth of xenografts in vivo and enhances chemosensitivity to 5-fluorouracil and paclitaxel. Mol Carcinog, 50(10):811-823, 2011.

41. Lei Li, Ye Gao, Linlin Zhang, Jin Zeng, Dalin He, Yi Sun. Silibinin inhibits cell growth and induces apoptosis by caspase activation, down-regulating survivin and blocking EGFR-ERK activation in renal cell carcinoma. Cancer Lett, 272: 61-69, 2008.

42. Jhy-Wen $\mathrm{Wu}, \mathrm{Li}-\mathrm{Chwen}$ Lin, Tung-Hu Tsai. Drugdrug interactions of silymarin on the perspective of pharmacokinetics. J Ethnopharmacol, 121: 185-193, 2009.

43. Yang Han, Dong Guo, Yao Chen, Yu Chen, ZhiRong Tan, Hong-Hao Zhou. Effect of silymarin on the pharmacokinetic of losartan and its active metabolite E-3174 in healthy Chinese volunteers. Eur J Clin Pharmacol,65:585-591,2009.

44. Jiaan Wein Deng, Ji-Hong Shon, Ho-Jung Shin,SooJin Park, Chang-Woo Yeo, Hong-Hao Zhou, ImSook Song, Jae-Gook Shin. Effect of silymarin 
supplement on the pharmacokinetic of rosuvastatin. Pharm Res, 25:1807-1814,2008.

45. A. Ghosh, T. Ghosh, S. Jain. Silymarin-areview on pharmacodynamics and bioavailability enhancement approaches. J Pharm Sci Technol,2(10): 348355,2010 .
46. Gholamreza Karimi, Maryam Vahabzadeh, Paisa Lari, Marziyeh Rashedinia, Mohammad Moshiri. "Silymarin", a promising pharmacological agent for treatment of diseases. Iranian Journal of Basic Medical Sciences, 14(4): 308-317,2011. 


\begin{tabular}{|c|c|c|c|c|c|}
\hline Study & Animal models & Administration plan & $\begin{array}{l}\text { Nephrotoxic } \\
\text { (injection) }\end{array}$ & Monitored indices & Results \\
\hline Gaedeke et al 1996 & female Wistar rats & silybin $200 \mathrm{mg} / \mathrm{kg}$ & Cisplatin 5mg/kg (IV) & $\begin{array}{l}\text { Enzymuria, magnesium } \\
\text { wasting, histology }\end{array}$ & $\begin{array}{lr}\text { Lower } & \text { enzymuria } \\
\text { and magnesium } \\
\text { wasting, } \\
\text { improvement and } \\
\text { histology in silybin } \\
\text { group }\end{array}$ \\
\hline Bokemeyer et al 1996 & Female Wistar rats & $\begin{array}{l}200 \mathrm{mg} / \mathrm{kg} 1 \mathrm{~h} \text { before } \\
\text { cisplatin injection IV } \\
\text { into the tail vein }\end{array}$ & $\begin{array}{l}\text { Cisplatin } 5 \mathrm{mg} / \mathrm{kg} \text { into the } \\
\text { tail vein (IP) }\end{array}$ & $\begin{array}{l}\text { Body weight, } 24 \mathrm{~h} \text { urine } \\
\text { volume and total urinary } \\
\text { AAPA activity, urinary Mg } \\
\text {,serum and urinary } \\
\text { creatinine, BUN }\end{array}$ & $\begin{array}{l}\text { No decrease in } \\
\text { creatinine clearance, } \\
\text { lower urea } \\
\text { concentration, } \\
\text { AAPA, and } \mathrm{Mg} \\
\text { wasting were noted } \\
\text { in silibinin treated } \\
\text { rats }\end{array}$ \\
\hline Karimi et al 2005 & male Wistar rats & $\begin{array}{l}\text { methanolic extract of } \\
\text { silymarin } 200 \mathrm{mg} / \mathrm{kg} 2 \mathrm{~h} \\
\text { before and after cisplatin } \\
\text { injection }\end{array}$ & $\begin{array}{l}\text { Cisplatin } 5 \mathrm{mg} / \mathrm{kg} \text { for } 5 \text { days } \\
\text { (IP) }\end{array}$ & BUN, creatinine, histology & $\begin{array}{l}\text { Lower BUN, SCr } \\
\text { levels, and tubular } \\
\text { necrosis in treatment } \\
\text { group }\end{array}$ \\
\hline Behling et al 2006 & Adult male Wistar rats & $\begin{array}{l}\text { Quercetin } 50 \mathrm{mg} / \mathrm{kg} 24 \\
\text { and } 1 \text { hour before } \\
\text { cisplatin administration } \\
\text { and were repeated daily } \\
\text { for } 2,5 \text { or } 20 \text { subsequent } \\
\text { days by gavage }\end{array}$ & Cisplatin $5 \mathrm{mg} / \mathrm{kg}$ by (IP) & $\begin{array}{l}\text { plasma creatinine, urine } \\
\text { volume and osmolality, } \\
\text { lipid peroxidation, renal } \\
\text { morphology }\end{array}$ & $\begin{array}{lr}\text { Quercetin treated } \\
\text { group had better } \\
\text { kidney } \\
\text { histopathology. } \\
\begin{array}{lr}\text { Quercetin } \\
\text { improved } \\
\text { creatinine, } \\
\text { peroxidation }\end{array}\end{array}$ \\
\hline $\begin{array}{l}\text { Abdelmeguid et al } \\
2010\end{array}$ & Sprague Dawley rats & $\begin{array}{l}\text { Silymarin } 50 \mathrm{mg} / \mathrm{kg} 2 \mathrm{~h} \\
\text { before and after cisplatin } \\
\text { injection }\end{array}$ & Cisplatin $5 \mathrm{mg} / \mathrm{kg}$ (IP) & $\begin{array}{l}\text { weight gain, kidney wet } \\
\text { weight, behavior change } \\
\text { and histology }\end{array}$ & $\begin{array}{l}\text { Lower kidney } \\
\text { weight to body } \\
\text { weight, } \\
\text { improvement in } \\
\begin{array}{l}\text { histology in the } \\
\text { silymarin treated } \\
\text { group }\end{array}\end{array}$ \\
\hline
\end{tabular}




\begin{tabular}{|c|c|c|c|c|c|}
\hline $\begin{array}{l}\text { Sanchez-Gonzalez et al } \\
2011\end{array}$ & $\begin{array}{l}\text { Rats inoculated by } \\
\text { breast adenocarcinoma } \\
\text { cells }\end{array}$ & $\begin{array}{l}\text { Quercetin } 50 \mathrm{mg} / \mathrm{kg} \text { for } \\
\text { four days (IP) }\end{array}$ & Cisplatin 4mg/kg (IP) & $\begin{array}{l}\text { Renal blood flow, GFR, } \\
\text { tubular necrosis/apoptosis, } \\
\text { lipid peroxidation, } \\
\text { antioxidant capacity, } \\
\text { inflammatory status }\end{array}$ & $\begin{array}{l}\text { quercetin partially } \\
\text { prevented all the } \\
\text { renal effects of } \\
\text { cisplatin }\end{array}$ \\
\hline Ninsonita et al 2011 & Human renal HK-2 cells & $\begin{array}{l}\text { Silymarin } 25- \\
\text { 200micromolar before }\end{array}$ & Cisplatin 25-100micromolar & $\begin{array}{l}\text { Cell apoptosis and necrosis } \\
\text { by Hoechst } 33342 \text { and } \\
\text { propidium iodide, cell } \\
\text { vitality by dimethyl- } \\
\text { diphenyl } \\
\text { bromide }\end{array}$ & $\begin{array}{lr}\text { Decreased cells } \\
\text { apoptosis, necrosis, } \\
\text { and death }\end{array}$ \\
\hline El-Shitany et al 2008 & Adult male albino rats & $\begin{array}{l}\text { Silymarin dose of } \\
50 \mathrm{mg} / \mathrm{kg} \text { seven days } \\
\text { before and daily for } 30 \\
\text { day (IP) }\end{array}$ & $\begin{array}{l}\text { Doxorubicin dosed } 10 \mathrm{mg} / \mathrm{kg} \\
\text { (IP) }\end{array}$ & $\begin{array}{l}\text { BUN, creatinine, tissue } \\
\text { change }\end{array}$ & $\begin{array}{l}\text { Lower rise in BUN, } \\
\mathrm{SCr} \text {, tissue change } \\
\text { in treatment group }\end{array}$ \\
\hline Varzi et al 2007 & Dogs & $\begin{array}{l}\text { silymarin } 20 \mathrm{mg} / \mathrm{kg} \text { daily } \\
\text { for nine days }\end{array}$ & $\begin{array}{l}\text { Gentamicin } 20 \mathrm{mg} / \mathrm{kg} \text { for } 9 \\
\text { days (IM) }\end{array}$ & $\begin{array}{l}\text { SrCr and urea and GFR and } \\
\text { MDA }\end{array}$ & $\begin{array}{l}\text { Lower SCr, serum } \\
\text { urea, and MDA and } \\
\text { higher GFR in } \\
\text { silymarin group }\end{array}$ \\
\hline $\begin{array}{l}\text { Ramachandran et al. } \\
2011\end{array}$ & Male Wistar albino rats. & $\begin{array}{l}\text { Silymarin at dose of } 50 \\
\mathrm{mg} / \mathrm{kg} \text { for six days by } \\
\text { oral rout }\end{array}$ & $\begin{array}{l}\text { Acetaminophen dose of } 750 \\
\mathrm{mg} / \mathrm{kg} \text { (IP) }\end{array}$ & $\begin{array}{l}\text { BUN, SrCr, uric acid, } \\
\text { catalase, } \\
\text { peroxidase }\end{array}$ & $\begin{array}{l}\text { Improved } \\
\text { BUN, uric acid, } \\
\text { catalase } \\
\text { glutathione } \\
\text { peroxidase }\end{array}$ \\
\hline Zima et al 1998 & Rats & $\begin{array}{l}\text { silibinin at dose of } \\
5 \mathrm{mg} / \mathrm{kg} 30 \mathrm{~min} \text { before } \\
\text { cyclosporine }\end{array}$ & $\begin{array}{l}\text { Cyclosporine dose of } \\
30 \mathrm{mg} / \mathrm{kg} \text { (IP) }\end{array}$ & $\begin{array}{l}\text { Serum Creatinine, MDA, } \\
\text { GFR }\end{array}$ & $\begin{array}{l}\text { Silibinin } r \\
\text { group had lower } \\
\text { lipid peroxidation } \\
\text { without } \\
\text { improvement } \mathrm{SCr} \text {, } \\
\text { GFR }\end{array}$ \\
\hline $\begin{array}{l}\text { Satayanarayana et al } \\
2001\end{array}$ & Rats & $\begin{array}{l}\text { Quercetin } 0.5 \text { or } 2 \mathrm{mg} / \mathrm{kg} \\
\text { one day before and daily } \\
\text { for } 21 \text { days }\end{array}$ & $\begin{array}{l}\text { Cyclosporine } 20 \mathrm{mg} / \mathrm{kg} / \text { day } \\
\text { for } 21 \text { days (SC) }\end{array}$ & $\begin{array}{l}\text { BUN, SrCr, arteriopathy, } \\
\text { glomerular basement } \\
\text { thickening, tubular } \\
\text { vacuolization and hyaline } \\
\text { casts }\end{array}$ & $\begin{array}{l}\text { Quercetin at dose of } \\
2 \mathrm{mg} / \mathrm{kg} / \text { day } \\
\text { improved renal } \\
\text { dysfunction }\end{array}$ \\
\hline
\end{tabular}

